\title{
Improvement of Soybean Oil Solvent Extraction through Enzymatic Pretreatment
}

\author{
F. V. Grasso, ${ }^{1}$ P. A. Montoya, ${ }^{1}$ C. C. Camusso, ${ }^{1,2}$ and B. G. Maroto ${ }^{1,2}$ \\ ${ }^{1}$ Facultad de Ciencias Exactas, Físicas y Naturales, Universidad Nacional de Córdoba, Avenue Velez Sarsfield 1200, \\ 5000 Córdoba, Argentina \\ ${ }^{2}$ Facultad de Ciencias Agropecuarias, Universidad Nacional de Córdoba, Avenue Valparaíso s/no, 5000 Córdoba, Argentina
}

Correspondence should be addressed to F. V. Grasso, fgrasso@agro.unc.edu.ar

Received 5 November 2011; Revised 14 February 2012; Accepted 6 March 2012

Academic Editor: Bertrand Matthäus

Copyright () 2012 F. V. Grasso et al. This is an open access article distributed under the Creative Commons Attribution License, which permits unrestricted use, distribution, and reproduction in any medium, provided the original work is properly cited.

\begin{abstract}
The purpose of this study is to evaluate multienzyme hydrolysis as a pretreatment option to improve soybean oil solvent extraction and its eventual adaptation to conventional processes. Enzymatic action causes the degradation of the cell structures that contain oil. Improvements in terms of extraction, yield, and extraction rate are expected to be achieved. Soybean flakes and collets were used as materials and hexane was used as a solvent. Temperature, $\mathrm{pH}$, and incubation time were optimized and diffusion coefficients were estimated for each solid. Extractions were carried out in a column, oil content was determined according to time, and a mathematical model was developed to describe the system. The optimum conditions obtained were $\mathrm{pH} 5.4,38^{\circ} \mathrm{C}$, and $9.7 \mathrm{~h}$, and $\mathrm{pH} 5.8,44^{\circ} \mathrm{C}$, and $5.8 \mathrm{~h}$ of treatment for flakes and collets, respectively. Hydrolyzed solids exhibited a higher yield. Diffusion coefficients were estimated between $10^{-11}$ and $10^{-10}$. The highest diffusion coefficient was obtained for hydrolyzed collets. $0.73 \mathrm{~g} \mathrm{oil} / \mathrm{mL}$ and $0.7 \mathrm{~g}$ oil $/ \mathrm{mL}$ were obtained at $240 \mathrm{~s}$ in a column for collets and flakes, respectively. Hydrolyzed solids exhibited a higher yield. The enzymatic incubation accelerates the extraction rate and allows for higher yield. The proposed model proved to be appropriate.
\end{abstract}

\section{Introduction}

Seed oils represent $70 \%$ of global oil production, of which $30 \%$ is soybean oil. Oilseeds are the most important export items in Argentina [1].

In oilseeds, the vacuoles within cells contain oil, and both cell walls and vacuoles have to be broken in order to improve solvent extraction. Therefore, the preparation of the seed before solvent extraction is critical to maximize oil recovery.

An alternative pretreatment to facilitate the release of oil from the seed could be enzymatic degradation. In this way, the partial hydrolysis of soybean seed cell structures with appropriate enzymes would increase permeability, which would in turn increase mass transfer [2]. An enzymatic treatment stage could be incorporated for industrial purposes without significant changes to conventional processes. The oil release obtained using this method could result in a higher extraction yield and/or smaller quantities of the organic solvents used [3].
In solvent extraction, pretreated oilseeds (porous solid matrix) come into contact with a pure solvent or a solvent mixture (miscella) to transfer the oil from the solid matrix to the liquid medium. While the principle of extraction is relatively simple, it is a complex mechanism [4]. In order to describe this process, the mass transfer phenomena involved and the eventual resistance to mass transfer in the solid phase (solid soybean) and in the liquid phase (hexane) should be analyzed. This process involves several phenomena: oil is diffused through the internal pores to the surface of the solid (internal mass transport) and is then passed to the bulk liquid by means of a convective mechanism produced by the concentration difference between the solution occluded in the pores and the bulk solution (external transport). Because the oil to be extracted is contained within an insoluble solid network with occluded miscella, the diffusion occurs mainly between the occluded solution and the solid, greatly affecting the extraction rate since the solid matrix resists diffusive transport [5]. 
The rate of conventive and diffusive mass transfer can be expressed by means of equations that predict that the transfer is proportional to the difference between the bulk and the liquid-solid interface concentration [6]. The mass transfer coefficient in the solid can be estimated from the effective diffusion coefficients, while the mass transfer coefficient in the liquid can be estimated from empirical correlations [7].

The purpose of this study is to evaluate multienzyme hydrolysis as a pretreatment option to improve soybean oil solvent extraction and, on the basis of the results obtained, to define a preparation stage adapted to existing industrial processes. For this evaluation, the optimum conditions for enzymatic treatment and the yield obtained in each case are determined first. Then, based on the reaction conditions optimized to maximize oil yield, the influence of the enzymatic hydrolysis on the diffusion as the ratedetermining step is established. Finally, a mathematical model for column extraction was developed to describe the process as an approximation to the operation of an industrial system.

\section{Materials and Methods}

2.1. Materials. Soybean flake and collet samples obtained from the industrial plant of Aceitera Bunge Argentina S.A., located in Córdoba, Argentina, were used. Industrial-grade enzymes provided by Genencor International were used as follows: Spezyme FRED ( $\alpha$-amylase activity), OPTIDEX L400 (glucoamylase activity), PEKTOZYME ULTRA C (pectinase activity), GC 440 (hemicellulase activity), MULTIFETC GC (cellulase activity), and MULTIFECT NEUTRAL (neutral protease activity). All enzymatic incubations were carried out in glass Erlenmeyer flasks in a rotary evaporator with temperature-regulated bath and agitation at $100 \mathrm{rpm}$. Analytical grade drugs supplied by Sigma and Merck were used. Buffer solutions pH 4.5, 5.0, 5.8, 6.6, and 7.2 were used. An analytical-grade $n$-hexane was used for extractions. The extractor used was a glass column with a reflux condenser to avoid solvent loss by evaporation and external jacket to control the temperature. The fixed bed was made up of flakes and collets with and without enzymatic hydrolysis. A peristaltic pump was used to supply the hexane.

\subsection{Methods}

Enzymatic Treatment. The solid sample was heated with buffer solution at working $\mathrm{pH}$ at $90^{\circ} \mathrm{C}$ for 15 minutes to inactivate the native lipase enzymes. The solid/liquid ratio was adjusted to $7: 1$. Each sample was treated with a multienzyme mixture (see Section 2.1) defined as optimal in previous studies [8]. Each sample was centrifuged at $3500 \mathrm{rpm}$ for 5 minutes. The centrifuged suspension was divided into two phases: a liquid and a solid phase. Each hydrolyzed solid fraction was dried in an oven at $60^{\circ} \mathrm{C}$ to constant weight in order not to alter the solid sample and to reduce the moisture content, which should not exceed $11 \%$ in order to avoid negative effects on the extraction rate and efficiency [9].
TAвLE 1: Natural variables and factor levels. Coded variables: $X_{1}=$ (T-50): $20 ; X_{2}=(\mathrm{pH}-5.8): 0.8 ; X_{3}=(t-8): 4$.

\begin{tabular}{lccccc}
\hline \multirow{2}{*}{ Natural variables } & \multicolumn{5}{c}{ Factor levels } \\
& -1.682 & -1 & 0 & +1 & +1.682 \\
\hline Temperature $(\mathrm{T})\left({ }^{\circ} \mathrm{C}\right)$ & 16.4 & 30 & 50 & 70 & 83.6 \\
$\mathrm{pH}$ & 4.45 & 5 & 5.8 & 6.6 & 7.15 \\
Time $(t)(\mathrm{h})$ & 1.3 & 4 & 8 & 12 & 14.7 \\
\hline
\end{tabular}

Optimization of Enzymatic Treatment. $\mathrm{pH}$, temperature, and incubation time conditions for each assay were determined according to a central composite experimental design with 3 variables. The design consisted in 20 experimental runs for each solid. Table 1 shows the experimental conditions for each assay.

The experimental design was based on the Response Surface Methodology (RSM) and included replications of the central point to minimize variance of the regression coefficients and axial points $(\alpha 1.681)$, so as to obtain a rotatable design [10]. The least-squares method was used to estimate the parameters of polynomial approximation. The analysis of the response surface was carried out according to the surface set.

Effective Diffusion Assays. The assays to evaluate effective diffusion were performed using collets and flakes and hydrolyzed samples and following the procedure described above. A cloth cartridge containing between 2 and $3 \mathrm{~g}$ of each sample was placed into an Erlenmeyer flask. $500 \mathrm{~mL}$ of hexane was added and the liquid medium was stirred to eliminate external resistance to mass transfer. Each experiment was conducted at $25^{\circ} \mathrm{C}$. At the end of time $t$, the cartridge with the sample was removed from the system. The experiments were carried out with 5-minute and 10-minute intervals until 1 hour of extraction was completed. Each sample was drained and dried to remove traces of solvent and moisture. After that, the samples were weighed and placed in a flask with pure hexane for batch extraction for $24 \mathrm{~h}$. The cartridge and the sample were dried once again in an oven in order to weigh the oil-free sample. The difference in weight before and after batch extraction was taken as the oil content at removal time $t$ out of the extractor.

Fixed Bed Column Extraction. The extractions to determine kinetics were carried out in a column, in which the fixed bed was made up of different soybean solids. The column was filled with these solids, which had been previously weighed. Pure hexane was used with temperature and flow defined from the top of the extractor. Miscella samples were taken at the exit of the extractor. The total extraction time was 60 minutes. $1 \mathrm{~mL}$ aliquots were taken at defined times. The oil in the miscellas obtained was determined spectrophotometrically at 280 and $300 \mathrm{~nm}$, according to the required sensitivity [11].

Estimation of Effective Diffusion Coefficients. The system diffusion was determined according to Fick's second law, as 
proposed by many authors [12-14], and Carrín and Crapiste [4]:

$$
\frac{\partial c}{\partial t}=\operatorname{Def} \frac{\partial^{2} c}{\partial x^{2}}
$$

with the following initial and boundary conditions for an unlimited and perfectly agitated volume of bulk liquid:

$$
\begin{aligned}
& \text { for } t=0, \quad c=c_{o}, \\
& \text { for } t>0, \quad c=0, \text { in } x=-l, x=l .
\end{aligned}
$$

The solution to (1) was obtained for plate and sphere, according to the solid that was considered. The following was obtained by integrating each solution and taking into account that the series obtained converge rapidly.

For plate with thickness $2 l$,

$$
\frac{q}{q_{0}}=\frac{8}{\pi^{2}} e^{-\pi^{2}\left(D t /(2 l)^{2}\right)} .
$$

For sphere with radius $r$,

$$
\frac{q}{q_{0}}=\frac{6}{\pi^{2}} e^{-\pi^{2}\left(\text { Def } \cdot t / r^{2}\right)} .
$$

Because the triglycerides present in vegetable oil have different molecular weights and structures, it is easier to measure the amount of oil in relation to solid mass. Therefore, the $c / c_{o}$ concentration ratio was turned into a $q / q_{0}$ quantity ratio in both equations [12]. Equations (3) and (4) were linearized and represented according to time $t$. The slope of both lines was used to evaluate the effective diffusion coefficients.

Mathematical Model for Column Extraction. The fixed bed was regarded as a section of an extraction column to which a steady stream of hexane, $Q_{L o}$, is supplied and from which the same flow of miscella, $Q_{L}$, is extracted. The mass balances for each phase were the following.

Solid:

$$
-\frac{d c_{S}}{d t}=\frac{k_{S} \cdot A}{V_{S}}\left(\hat{c_{S}}-\mathrm{Keq} \cdot c_{L}\right) .
$$

Liquid:

$$
\frac{d c_{L}}{d t}=-\frac{Q_{L} \cdot c_{L}}{V_{L}}+\frac{k_{L} \cdot A}{V_{L}}\left(\frac{\widehat{c_{S}}}{\mathrm{Keq}}-c_{L}\right) .
$$

In the mass balance estimation, it was assumed that the bed was made up of porous particles-isotropic and spherical particles for collets with and without enzymatic pretreatment and for flakes with enzymatic treatment. The oil content in each of the solids is uniform in all particles, and the oil behaves as a single component, since its triglycerides are highly soluble in hexane [12]. The solids contain macropores in which the oil globules reside; the solvent penetrates these pores and dissolves the oil instantly, forming the miscella (stagnant phase) [4, 15]. An equilibrium relationship is established between the oil content in the stagnant phase in the pores and the residual oil content in the solid. The oil transfer occurs from the pores to the miscella due to the oil concentration gradient. The column length-particle diameter ratio is high enough to neglect the radial concentration gradient. The porosities of the bed and particle are uniform and constant throughout the extraction process. No heat of mixing is produced, and the temperature is constant and uniform throughout the extraction. The equilibrium relationship determined experimentally includes the effect of solid moisture; the volumetric flow is constant because the flow of pure hexane supplied into the system is equal to the flow of miscella extracted from the system. The mass transfer constants in the liquid were estimated using the empirical correlation for fixed beds proposed by Geankoplis [6] and the mass transfer constants in the solid phase were estimated by equaling (5) (mass balance) with the equations that describe the diffusive phenomenon, taking into account the corrections due to material porosity [16]. The solution to (5) and (6) was numerically found using MatLab 2008a.

\section{Results and Discussion}

Optimization of Enzymatic Treatment. The amount of oil that can be extracted from soybean flakes using the Soxhlet method is $16 \%$ on the dry basis (DB), and $18.54 \%$ (DB) for soybean collets. An increase in yield is observed for all experimental runs with enzymatic pretreatment (see Table 2).

The RSM analysis enabled us to obtain the experimental conditions for the enzymatic aqueous pretreatment, through which the maximum theoretical yield in oil (\% DB) is obtained for each type of starting material.

The ANOVA analysis (see Table 3 ) was used to define the polynomial coefficients of the response.

(a) Flakes. Both linear and quadratic effects of temperature were significant, exceeding 95\% of confidence level in both cases, and so did the quadratic effect of incubation time. For the $\mathrm{pH}$ variable, the variation was not statistically significant $(P>0.05)$. It can also be inferred that there were no significant effects for interaction terms between variables. Therefore, the response function was defined as $Y(\%)=$ $27.055-0.06 T-3.68 T^{2}-0.04 t^{2}+$ error.

(b) Collets. The quadratic effects of temperature and incubation $\mathrm{pH}$ were significant, exceeding $98 \%$ of confidence level in both cases, and so did the crossover effect of $\mathrm{pH}$ and incubation time. For the other linear terms, the variation was not statistically significant $(P>0.05)$. It can also be inferred that there were no significant effects for interaction terms between the temperature and incubation time variables. Therefore, the response function was defined as $Y(\%)=$ $26.566+0.186 \mathrm{pH} \cdot t-3.10 \mathrm{~T}^{2}-0.7274 \mathrm{pH}^{2}+$ error.

As it can be observed, the $P$ value indicates that the model is significant for all cases with more than $98 \%$ of confidence. On the other hand, the adequacy of the quadratic model with 98\% confidence, a 1.347 total error for flakes and 0.864 for collets, and a nonsignificant lack of fit with a confidence level greater than $96 \%$ for the two starting materials was proved. 
TABle 2: Percent of oil yield for experimental design assays.

\begin{tabular}{lccccc}
\hline \multirow{2}{*}{ Assay } & \multicolumn{3}{c}{ Coded variables } & \multicolumn{2}{c}{ Yield $Y$ (Oil \%) } \\
& $X_{1}$ & $X_{2}$ & $X_{3}$ & Flakes & Collets \\
\hline 1 & -1.41 & 0 & 0 & 25.79 & 24.26 \\
2 & +1.41 & 0 & 0 & 21.39 & 21.58 \\
3 & 0 & -1.41 & 0 & 28.02 & 24.93 \\
4 & 0 & +1.41 & 0 & 25.53 & 25.30 \\
5 & 0 & 0 & -1.41 & 25.31 & 24.37 \\
6 & 0 & 0 & +1.41 & 26.85 & 26.01 \\
7 & -1 & -1 & -1 & 25.45 & 25.83 \\
8 & +1 & -1 & -1 & 22.00 & 25.46 \\
9 & -1 & +1 & -1 & 24.00 & 25.01 \\
10 & +1 & +1 & -1 & 23.62 & 23.19 \\
11 & -1 & -1 & +1 & 26.13 & 24.33 \\
12 & +1 & -1 & +1 & 21.55 & 23.11 \\
13 & -1 & +1 & +1 & 26.47 & 23.14 \\
14 & +1 & +1 & +1 & 23.87 & 25.98 \\
15 & 0 & 0 & 0 & 27.88 & 26.19 \\
16 & 0 & 0 & 0 & 26.28 & 26.73 \\
17 & 0 & 0 & 0 & 26.34 & 26.78 \\
18 & 0 & 0 & 0 & 26.47 & 26.38 \\
19 & 0 & 0 & 0 & 28.46 & 26.65 \\
20 & 0 & 0 & 0 & 26.62 & 26.68 \\
\hline & & & & &
\end{tabular}

For soybean flakes, the variable with the greatest influence is temperature; most enzymes used in the assays have similar optimum temperature ranges, which coincide with the maximum yield temperature. This yield is a direct function of the overall enzymatic activity, since it facilitates the release of oil through the degradation of cell structures. No significant variation in yield was observed in relation to the change in $\mathrm{pH}$. This may be due to the narrow range of study and the great variety of enzymes used. Each of them has its own optimum pH: when one of them is at maximum activity, the others exhibit minor activity because they do not have their optimum $\mathrm{pH}$. This assumption is strengthened by the fact that the extraction efficiency is not the result of the sum of individual activity [17]. For soybean collets, the three variables studied are significant to varying degrees. The greatest difference was observed for the $\mathrm{pH}$ variable in multienzyme hydrolysis. This may be due to the different structure of the solid. The soybean collets are obtained by combining hydrothermal and mechanical treatments. Heattreated materials exhibit a greater influence regarding the $\mathrm{pH}$ variable, probably due to the fact that the effect of proteases on yield is more significant than carbohydrolase activity in this type of material [18]. The optimum $\mathrm{pH}$ for the proteases used is in the 5.5-6 range, while carbohydrolases exhibit optimum $\mathrm{pH}$ ranges closer to 5 .

Table 4 summarizes the optimum conditions found for maximum oil yield for each of the solid materials tested. These optimal conditions were determined by deriving and setting the response function (stationary point) equal to zero.
Best yields were obtained for soybean flakes $(27.59 \%$ DB); the combination of several pretreatments produces an improvement in yield. In the case of soybean collets, which go through solvent extraction directly, a lower yield (26.64\% DB) was obtained when compared to flakes. These results agree with those obtained by Rosenthal et al. [18], who found higher extraction yields for non-heat-treated materials (flakes) than those for heat-treated materials (collets). This may be attributable to lower hydrolysis rates for heatdenatured substrates than those obtained with non-heattreated materials [18].

Estimation of Effective Diffusion Coefficients. Table 5 shows the effective diffusion coefficients estimated for all materials without external resistance to mass transport and when the internal transport of material is due diffusional processes exclusively.

The coefficient values are calculated on the basis of the slope estimated for each of the fitted lines, linearizing (3) and (4). As it can be observed, the magnitude order of the estimated diffusion coefficients was between $10^{-11}$ and $10^{-10} \mathrm{~m}^{2} \cdot \mathrm{s}^{-1}$, which coincides with previous data [19-27]. Varzakas et al. [5] compiled effective diffusion coefficients in magnitude orders between $10^{-12}$ and $10^{-10} \mathrm{~m}^{2} \cdot \mathrm{s}^{-1}$ for a wide variety of solid foods, and so did Doulia et al. [19]. Diffusion through solids is more complex than diffusion through gases or liquids, that is why, in most cases, smaller diffusion coefficients are observed, and, therefore, mass transfer occurs more slowly. In all the cases studied, and considering unidirectional diffusion and plate and sphere geometries for the starting solid, oil extraction with hexane followed the model of nonstationary diffusion proposed by Fick's second law. It can be observed that the effective diffusion coefficient was higher for solids which have gone through more pretreatments, which is consistent with the degradation degree of cell structures. If the starting material is an enzymatically pretreated solid with degraded cell structures, the material has higher permeability to the extraction solvent and the movement of oil molecules into the bulk solution meets fewer physical barriers.

Mathematical Model for Column Extraction. The solution to (5) and (6) was obtained through the method of numerical differentiation formula with the MatLab 2008a tool. From these solutions, the simulated profile of oil content evolution in miscella at the column exit and the simulated profile of residual oil content evolution in the solid were estimated $[7,15,16,27,28]$. Figures 1 and 2 show the simulated data of oil concentration in miscella at the exit of the extraction column according to time for solid flakes and collets without enzymatic pretreatment, respectively. Figures 3 and 4 show the experimental and simulated profiles for solid flakes and collets with enzymatic pretreatment. Each Figure shows both the values obtained in experimental manner and those estimated with the model.

The figures show good correspondence between experimental data and values estimated with the model used for this experimental scheme and the extraction equipment 
TABLE 3: ANOVA results for yield optimization in oil.

(a) Soybean flakes

\begin{tabular}{|c|c|c|c|c|c|}
\hline & SS & FG & MS & $F$ & $P$ value \\
\hline Model & 67.089 & 9 & 7.454 & 5.534 & 0.0066 \\
\hline Error & 13.471 & 10 & 1.347 & & \\
\hline Total fit & 80.569 & 19 & 4.240 & & \\
\hline Quadratic fit & 39.932 & 6 & 6.655 & 4.941 & 0.0134 \\
\hline Lack of fit & 9.158 & 5 & 1.832 & 2.123 & 0.2401 \\
\hline Pure error & 4.313 & 5 & 0.863 & & \\
\hline Total error & 13.471 & 10 & 1.347 & & \\
\hline
\end{tabular}

(b) Soybean collets

\begin{tabular}{|c|c|c|c|c|c|}
\hline & SS & FG & MS & $F$ & $P$ value \\
\hline Model & 32.550 & 9 & 3.617 & 4.188 & 0.0178 \\
\hline Error & 8.636 & 10 & 0.864 & & \\
\hline Total fit & 41.186 & 19 & 2.168 & & \\
\hline Quadratic fit & 30.609 & 6 & 5.102 & 5.907 & 0.0072 \\
\hline Lack of fit & 8.364 & 5 & 1.673 & 30.729 & 0.0009 \\
\hline Pure error & 0.272 & 5 & 0.054 & & \\
\hline Total error & 8.636 & 10 & 0.864 & & \\
\hline
\end{tabular}

TABle 4: Optimum enzymatic incubation conditions to obtain maximum theoretical oil yield.

\begin{tabular}{lccc}
\hline & $\mathrm{pH}$ & Temperature $\left({ }^{\circ} \mathrm{C}\right)$ & Time $(\mathrm{h})$ \\
\hline Flakes & 5.4 & 38 & 9.7 \\
Collets & 5.8 & 43.5 & 5.8 \\
\hline
\end{tabular}

TABle 5: Estimated effective diffusion coefficients at $25^{\circ} \mathrm{C}$.

\begin{tabular}{|c|c|c|c|}
\hline & Slope & $\begin{array}{l}\text { Equivalent } \\
\text { size }(\mathrm{m})\end{array}$ & $\begin{array}{l}\text { Effective diffusion } \\
\text { coefficient }\left(\mathrm{m}^{2} \cdot \mathrm{s}^{-1}\right)\end{array}$ \\
\hline Flakes (plate) & -0.0064 & $l=0.00045$ & $0.88 \cdot 10^{-11}$ \\
\hline Collets (sphere) & -0.007 & $R=0.00375$ & $1.67 \cdot 10^{-10}$ \\
\hline $\begin{array}{l}\text { Hydrolyzed } \\
\text { flakes (sphere) }\end{array}$ & -0.0084 & $R=0.00375$ & $4.60 \cdot 10^{-11}$ \\
\hline $\begin{array}{l}\text { Hydrolyzed } \\
\text { collets (sphere) }\end{array}$ & -0.0111 & $R=0.00375$ & $2.63 \cdot 10^{-10}$ \\
\hline
\end{tabular}

$R$ : sphere radius; $l$ : plate thickness.

used. As it can be observed, the maximum amount of oil was obtained for the bed made up of hydrolyzed soybean collets. After $240 \mathrm{~s}$ of contact, the exiting miscella contained $0.73 \mathrm{~g} / \mathrm{mL}$ of oil, compared to $0.7 \mathrm{~g} / \mathrm{mL}$ of oil for hydrolyzed flakes. On the other hand, the graphs showed that the lowest value obtained corresponded to the bed made up of soybean flakes without hydrolysis. After about 2 minutes of extraction, the exiting miscella contained approximately $0.14 \mathrm{~g} \mathrm{oil} / \mathrm{mL}$. It was observed that the maximum amount of oil obtained for soybean collets without hydrolysis $(0.46 \mathrm{~g} / \mathrm{mL})$ is more than twice as much as the maximum value for soybean flakes without hydrolysis $(0.14 \mathrm{~g} / \mathrm{mL})$. The difference could be due to the influence of the degree of cell

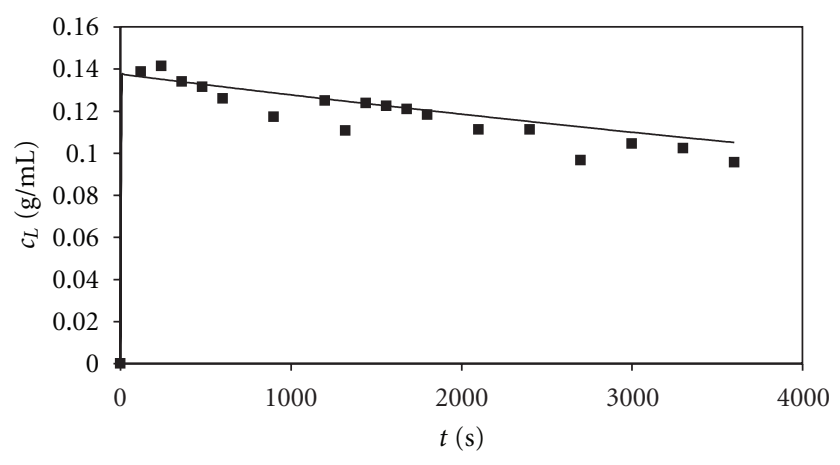

Figure 1: Evolution of oil content at the exit of the extraction column for flakes.

structure destruction on oil diffusion in the solid, and it is a significant difference considering the high solubility of oil in hexane (solvent). Higher oil content was observed in the miscella at the exit of the column for shorter extraction times if hydrolyzed flakes are used instead of hydrolyzed collets. These results agree with the maximum yields obtained in the optimization stage.

\section{Conclusions}

The optimization of the $\mathrm{pH}$, temperature, and enzymatic hydrolysis time variables led to maximum oil yield as follows: for flakes, incubation at $\mathrm{pH} 5.4$ and $38^{\circ} \mathrm{C}$ for $9.7 \mathrm{~h}$ and, for collets, incubation at $\mathrm{pH} 5.8$ and $43.5^{\circ} \mathrm{C}$ for $5.8 \mathrm{~h}$. With enzymatic pretreatment, the oil yield obtained is greater than that obtained for conventional extraction without enzymatic 


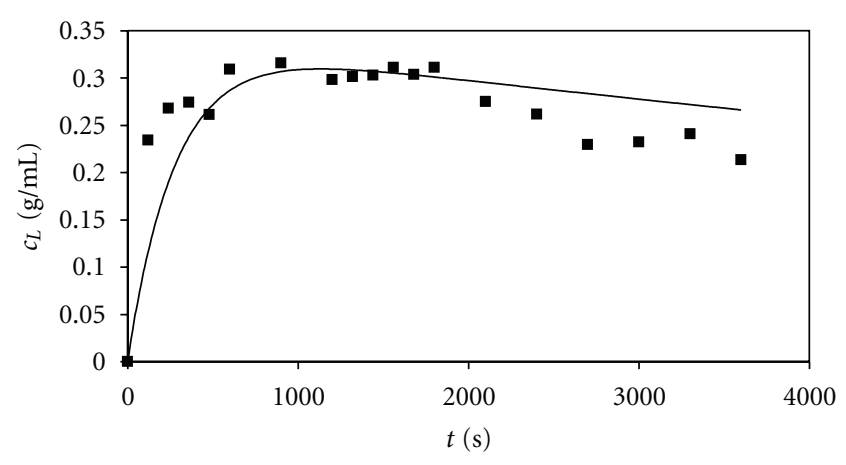

Figure 2: Evolution of oil content at the exit of the extraction column for collets.

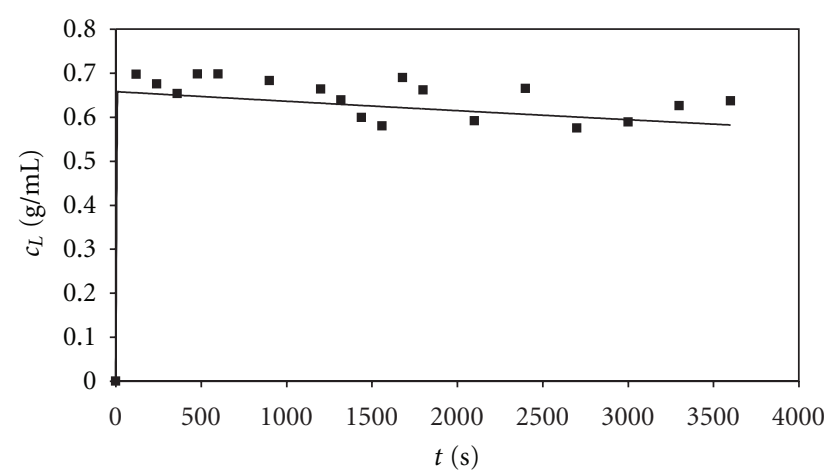

FIGURE 3: Evolution of oil content at the exit of the extraction column for hydrolyzed flakes.

treatment: $27.59 \%$ for soybean flakes, $26.64 \%$ for soybean collets.

It was determined that enzymatic hydrolysis decreases the integrity of plant tissues, increasing the permeability of these structures to oil, which results in greater diffusion coefficients for batch extraction in the absence of external resistance to oil transport.

The enzymatically treated soybean solids exhibited higher extraction rates and better yield for extracted oil. While the maximum rate of oil extraction with hexane in a fixed bed column is obtained when using enzymatically pretreated collets, the difference in extraction rate is not significant when compared to the use of hydrolyzed flakes.

The mass transfer phenomenon that determines the extraction rate was the oil diffusion that takes place within the solid. The proposed mathematical model of macroscopic balance proved to be appropriate to describe the fixed bed column extraction system.

Based on these conclusions, we can state that enzymatic hydrolysis is a new pretreatment option that could be incorporated into the current processes of soybean oil solvent extraction. The improvements obtained could be applied at industrial level and result in faster extraction processes, higher oil yield and/or decreased amount of solvent used.

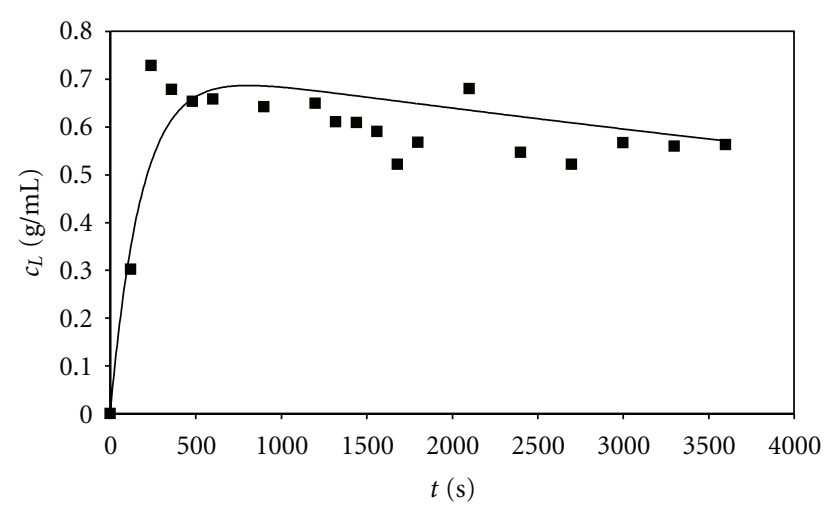

FIgURE 4: Evolution of oil content at the exit of the extraction column for hydrolyzed collets.

\section{Nomenclature}

A: $\quad$ Specific surface for mass transfer, $\mathrm{m}^{2} \cdot \mathrm{m}^{-3}$

c: Oil concentration, $\mathrm{Kg} \cdot \mathrm{m}^{-3}$

$D$ : Diffusion coefficient, $\mathrm{m}^{2} \cdot \mathrm{s}^{-1}$

DF: Degree of freedom

F: Fisher test

$k$ : $\quad$ Mass transfer coefficient, $\mathrm{m} \cdot \mathrm{s}^{-1}$

$K$ : Equilibrium constant

$l$ : $\quad$ Thickness of the plane sheet, $\mathrm{m}$

MS: Mean squares

$q$ : Oil mass, $\mathrm{g}$

Q: Caudal, $\mathrm{m}^{3} \cdot \mathrm{s}^{-1}$

$r$ : Radius of the sphere, $\mathrm{M}$

SS: Sum of squares

$t$ : Time, $s$

$V:$ Volume, $\mathrm{m}^{3}$

$x$ : Characteristic dimension for diffusion, $\mathrm{m}$

$Y$ : Oil yield.

\section{Subscripts}

ef: Effective

eq: Equilibrium

L: Liquid

$o:$ Initial

S: Solid.

\section{Acknowledgments}

This study was funded by the Department of Science and Technology (SeCyT) of the National University of Cordoba. The authors would like to thank Genencor International Inc. for providing the enzymes and Bunge Argentina S.A. for providing samples of soybean collets.

\section{References}

[1] Aceites y Grasas, "China y Argentina: el crushing de soja," Aceites y Grasas, vol. 74, pp. 36-37, 2009. 
[2] A. Rosenthal, D. L. Pyle, and K. Niranjan, "Aqueous and enzymatic extraction of editable oils from oilseeds," Enzyme and Microbial Technology, vol. 19, p. 401, 1996.

[3] D. Shankar, Y. C. Agrawal, B. C. Sarkar, and B. P. N. Singh, "Enzymatic hydrolysis in conjunction with conventional pretreatments to soybean for enhanced oil availability and recovery," JAOCS, vol. 74, no. 12, pp. 1543-1547, 1997.

[4] M. E. Carrín and G. H. Crapiste, "Mathematical modeling of vegetable oil-solvent extraction in a multistage horizontal extractor," Journal of Food Engineering, vol. 85, no. 3, pp. 418425,2008

[5] T. H. Varzakas, G. C. Leach, C. J. Israilides, and D. Arapaglou, "Theoretical and experimental approaches towards the determination of solute effective diffusivities in foods," Enzyme and Microbial Technology, vol. 37, p. 29, 2005.

[6] C. J. Geankoplis, Procesos de Transporte y Operaciones Unitarias, CECSA, San Luis Potosi, Mexico, 3rd edition, 1998.

[7] M. Pramparo, S. Gregory, and M. Mattea, "Immersion vs. percolation in the extraction of oil from oleaginous seeds," JAOCS, vol. 79, no. 10, pp. 955-960, 2002.

[8] F. Grasso, B. Maroto, and C. Camusso, Pretratamiento Enzimático Para Mmejorar la Extracción de Aceite por Solvente, XIX Jornadas IRAM-Universidades y IV Foro Unilab, San Luis, Argentina, 2003.

[9] H. Domínguez, M. J. Núñez, and J. M. Lema, "Enzymeassisted hexane extraction of soya bean oil," Food Chemistry, vol. 54, no. 2, pp. 223-231, 1995.

[10] D. C. Montgomery, Design and Analysis of Experiment, John Wiley \& Sons, New York, NY, USA, 1991.

[11] K. L. Wiese and H. E. Snyder, "Analysis of the oil extraction process in soybeans: a new continuous procedure," JAOCS, vol. 64, no. 3, pp. 402-406, 1987.

[12] H. P. Fan, J. C. Morris, and H. Wakenham, "Diffusion phenomena in solvent extraction of peanut oil," Industrial and Engineering Chemistry, vol. 40, no. 2, pp. 195-199, 1948.

[13] A. S. Smith, "Evaluation of extraction rate measurements," JAOCS, vol. 29, pp. 421-425, 1952.

[14] J. Sineiro, H. Dominguez, and M. J. Núñez, "Influencia del tratamiento enzimático en la calidad de aceites vegetales," Grasas y Aceites, vol. 49, p. 191, 1998.

[15] G. C. Majumdar, A. N. Samanta, and S. P. Sengupta, "Modeling solvent extraction of vegetable oil in a packed bed," JAOCS, vol. 72, no. 9, pp. 971-979, 1995.

[16] J. D. Espinoza-Pérez, A. Vargas, V. J. Robles-Olvera, G. C. Rodríguez-Jimenes, and M. A. García-Alvarado, "Mathematical modeling of caffeine kinetic during solid-liquid extraction of coffee beans," Journal of Food Engineering, vol. 81, no. 1, pp. 72-78, 2007.

[17] E. M. Düsterhöft, A. W. Bonte, J. C. Venekamp, and A. G. J. Voragen, "The role of fungal polysaccharidases in the hydrolysis of cell wall materials from sunflower and palmkernel meals," World Journal of Microbiology \& Biotechnology, vol. 9, no. 5, pp. 544-554, 1993.

[18] A. Rosenthal, D. L. Pyle, K. Niranjan, S. Gilmour, and L. Trinca, "Combined effect of operational variables and enzyme activity on aqueous enzymatic extraction of oil and protein from soybean," Enzyme and Microbial Technology, vol. 28, no. 6, pp. 499-509, 2001.

[19] D. Doulia, K. Tzia, and V. Gekas, "A knowledge base for the apparent mass diffusion coefficient (DEFF) of foods," International Journal of Food Properties, vol. 3, no. 1, pp. 1-14, 2000.

[20] A. S. Pajonk, R. Saurel, and J. Andrieu, "Experimental study and modeling of effective $\mathrm{NaCl}$ diffusion coefficients values during Emmental cheese brining," Journal of Food Engineering, vol. 60, no. 3, pp. 307-313, 2003.
[21] E. Simeonov, I. Tsibranska, and A. Minchev, "Solid-liquid extraction from plants-experimental kinetics and modelling," Chemical Engineering Journal, vol. 73, no. 3, pp. 255259, 1999.

[22] J. E. Cacace and G. Mazza, "Mass transfer process during extraction of phenolic compounds from milled berries," Journal of Food Engineering, vol. 59, no. 4, pp. 379-389, 2003.

[23] J. A. Pérez-Galindo, J. López-Miranda, and I. R. MartínDominguez, "Geometric and Reynolds Lumber effects on oregano (Lippia Berlaudieri Schaver) essencial oil extraction," Journal of Food Engineering, vol. 44, p. 127, 2000.

[24] I. Seikova, E. Simeonov, and E. Ivanova, "Protein leaching from tomato seed-Experimental kinetics and prediction of effective diffusivity," Journal of Food Engineering, vol. 61, no. 2, pp. 165-171, 2004.

[25] J. Welti-Chanes, F. Vergara-Balderas, and D. BermúdezAguirre, "Transport phenomena in food engineering: basic concepts and advances," Journal of Food Engineering, vol. 67, no. 1-2, pp. 113-128, 2005.

[26] Y. Chalermchat, M. Fincan, and P. Dejmek, "Pulsed electric field treatment for solid-liquid extraction of red beetroot pigment: mathematical modelling of mass transfer," Journal of Food Engineering, vol. 64, no. 2, pp. 229-236, 2004.

[27] C. Mantell, M. Rodriguez, and E. Martinez de la Ossa, "Semibatch extraction of anthocyanins from red grape pomace in packed beds: experimental results and process modellling," Chemical Engineering Science, vol. 57, p. 3831, 2002.

[28] M. J. Rivero Martinez, Diseño del proceso de purificación de estireno mediante adsorción en alumina, thesis, Cantabria University, 2002. 


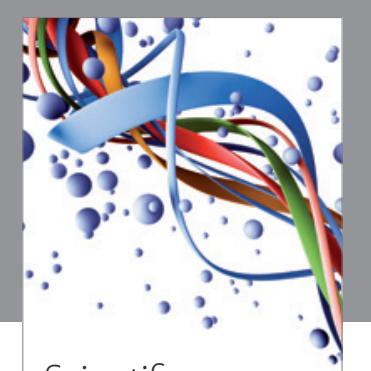

Scientifica
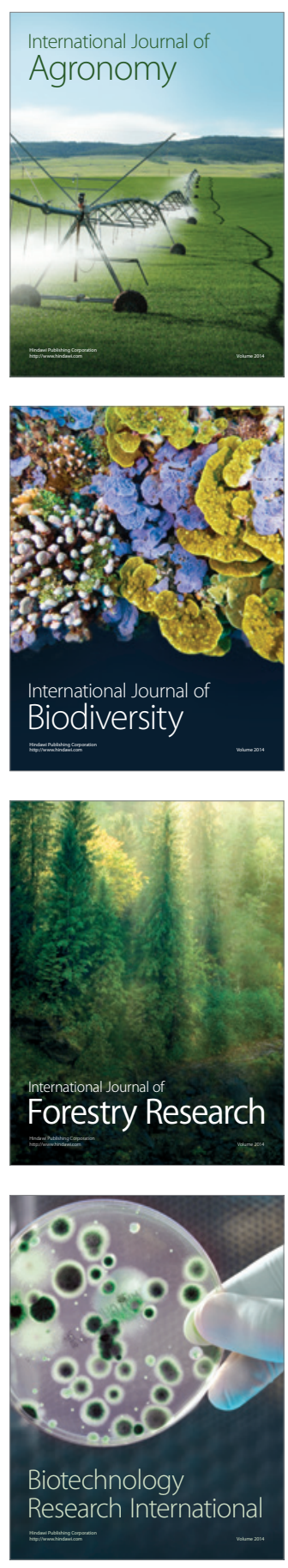
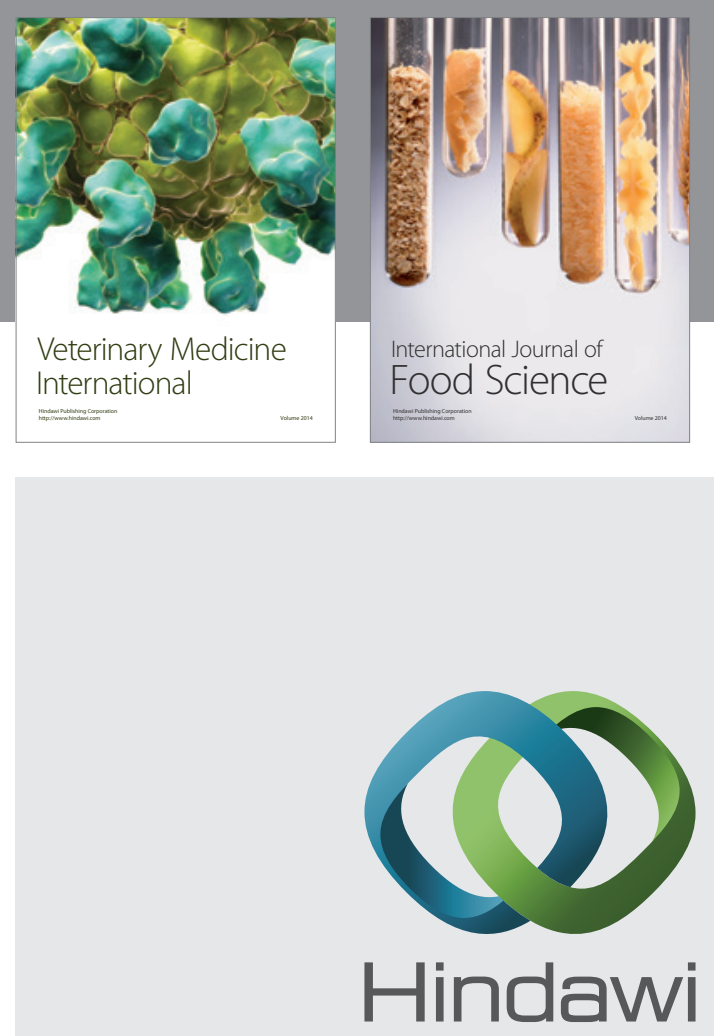

Submit your manuscripts at

http://www.hindawi.com
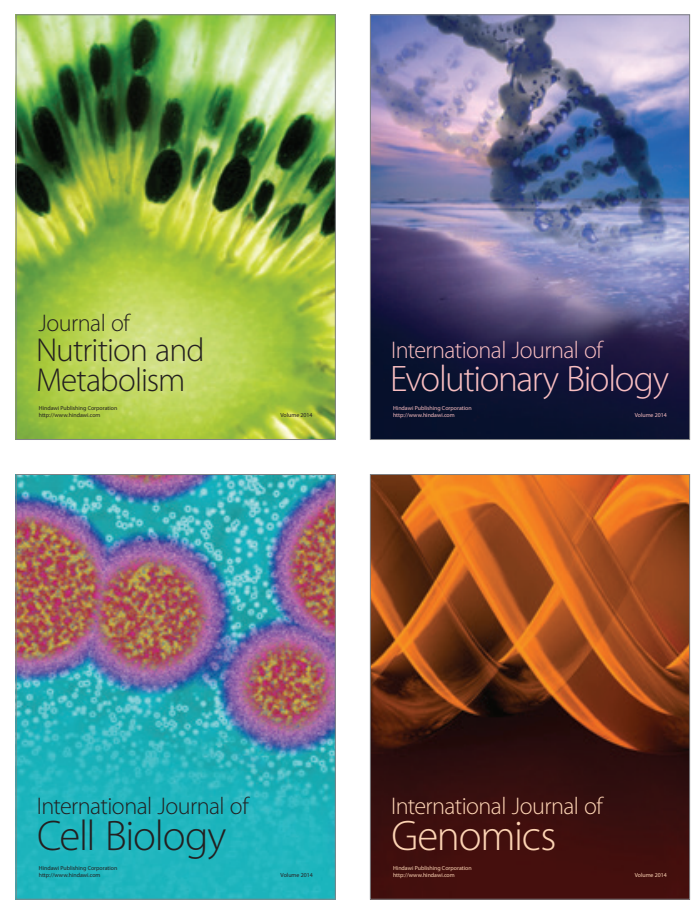
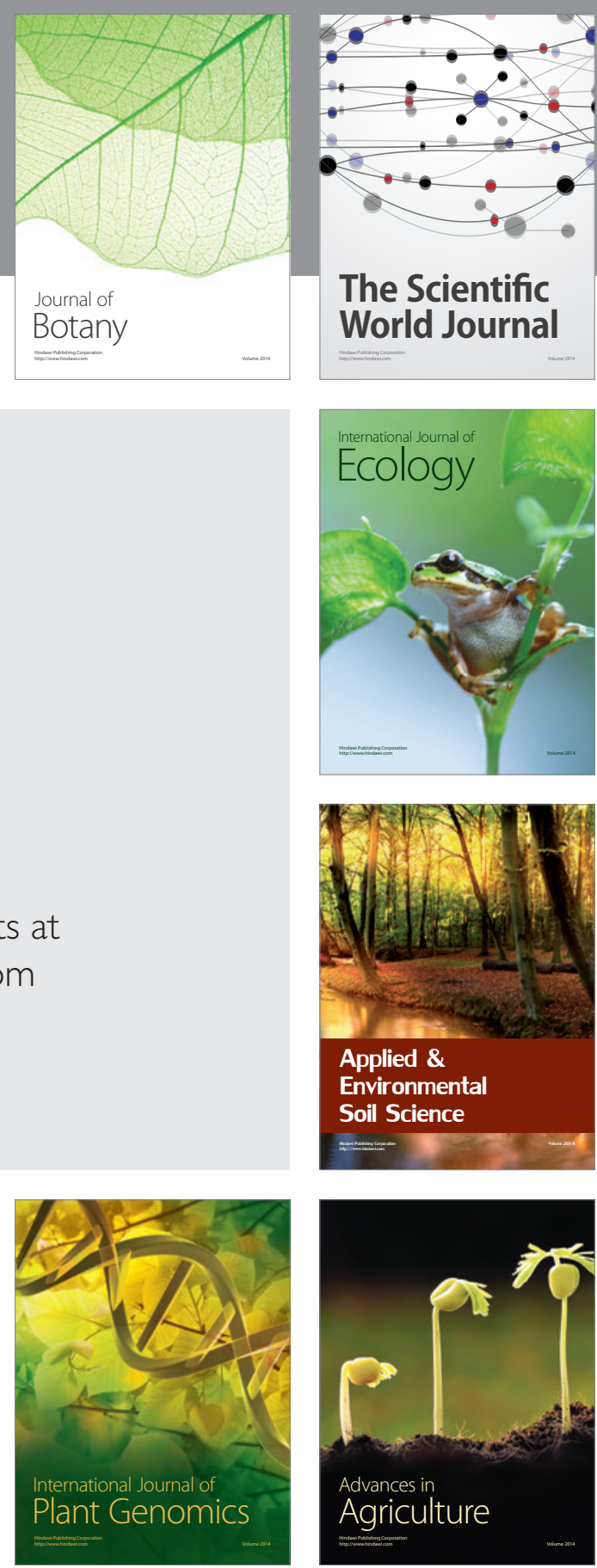

The Scientific World Journal
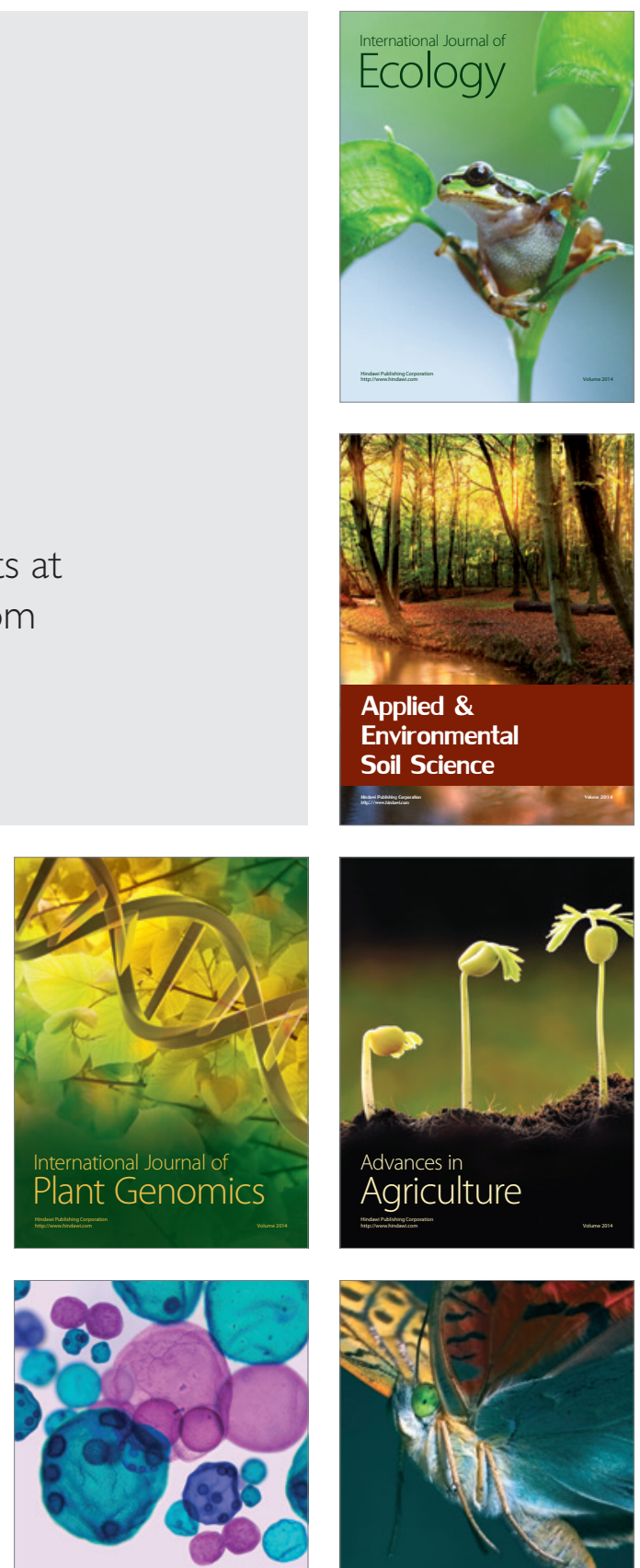

International Journal of Microbiology

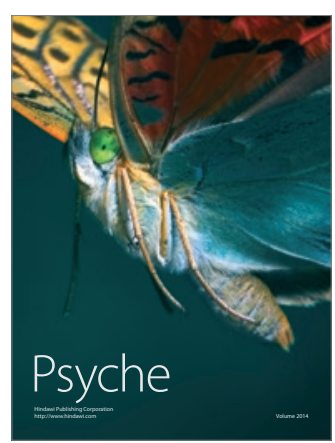

